\title{
Effect of different air-abrasion protocols on topography, surface wettability and adhesion of MDP monomer-based resin cement to zirconia
}

\author{
Massi Paschoalino, Vivian ; Juste Paschoalino, Bruno ; Özcan, Mutlu ; Luis Almeida de Carvalho, \\ Ronaldo ; de Carvalho, Rodrigo Furtado ; Al-Haj Husain, Nadin ; Pessoa Pereira Leite, Fabiola
}

\begin{abstract}
This study evaluated the effect of air-abrasion protocols on the topography, surface wettability and adhesion of resin cement to zirconia. Ceramic specimens $(\mathrm{N}=49 ; \mathrm{n}=7)(15 \mathrm{~mm} \times 2 \mathrm{~mm})$ were randomly allocated to seven groups to be treated with: (1) Air-abrasion with $45 \mathrm{~m} \mathrm{Al2O} 3$ (A45), (2) $80 \mathrm{~m} \mathrm{Al} 2 \mathrm{O} 3$ (A80), (3) $30 \mathrm{~m}$ Al2O3 coated with SiO2 (CoJet) (C30), (4) $30 \mathrm{~m}$ Al2O3 coated with SiO2 (Rocatec Soft) (R30), (5) 110 m Al2O3 coated with SiO2 (Rocatec Plus) (R110); (6) R110R30 (Rocatec) (R110R30) and (7) control, no conditioning (NC). Air-abrasion was performed using a chairside air-abrasion device (2.5 bar, $10 \mathrm{~mm}, 90 \mathrm{~s})$. Contact angle measurements were performed using goniometry $(\mathrm{n}=5)$. MDP-based dual resin cement (Panavia F2.0) was bonded on four locations after air-abrasion protocols $(\mathrm{n}=20$ per group). Half of the specimens were tested after $24 \mathrm{~h}$ and the other half after thermal cycling $\left(\times 3000,5-55^{\circ} \mathrm{C}\right)$. Data were analyzed using $1-, 2$-way ANOVA and Tukey's test (alpha $=0.05)$. Significantly lower contact angle values were observed for groups C30 (62.6 \pm 0.91$)$, R30 (61.91 $\pm 1.05)$ and R110R30 $(61.54 \pm 1.02)$ compared to those of other groups $(65.5 \pm 0.9-110.61 \pm 0.9)(\mathrm{p}$ $<0.05)$. In dry conditions, surface conditioning methods tested did not show significant effect on bond strength $(\mathrm{MPa})(10.57 \pm 1.42-16.86 \pm 2.54)(\mathrm{p}=0.238)$. After thermocycling, bond strength results decreased significantly $(\mathrm{p}<0.05)(12.6-51.2 \%) . \quad \mathrm{R} 110(7.18 \pm 1.34)$ and A80 (4.92 \pm 1.53$)$ showed significantly higher bond strength compared to other groups $(2.13 \pm 0.73-4.16 \pm 1.34)(\mathrm{p}<0.05)$. The best wettability and adhesion results with MDP-based resin cement to zirconia was achieved with A80 and R110 air-abrasion.
\end{abstract}

DOI: https://doi.org/10.1080/01694243.2019.1620404

Posted at the Zurich Open Repository and Archive, University of Zurich

ZORA URL: https://doi.org/10.5167/uzh-183093

Journal Article

Accepted Version

Originally published at:

Massi Paschoalino, Vivian; Juste Paschoalino, Bruno; Özcan, Mutlu; Luis Almeida de Carvalho, Ronaldo; de Carvalho, Rodrigo Furtado; Al-Haj Husain, Nadin; Pessoa Pereira Leite, Fabiola (2019). Effect of different air-abrasion protocols on topography, surface wettability and adhesion of MDP monomer-based resin cement to zirconia. Journal of Adhesion Science and Technology, 33(17):1948-1958.

DOI: https://doi.org/10.1080/01694243.2019.1620404 
Effect of different air-abrasion protocols on topography, surface wettability and adhesion of MDP monomer-based resin cement to zirconia

Vivian Massi Paschoalino, DDSa / Bruno Juste Paschoalino, DDS / Mutlu Özcan, DDS, Dr.med.dent., Ph.Dc / Ronaldo Luis Almeida de Carvalho, DDSd / Rodrigo Furtado de Carvalho, DDSe / Nadin Al-Haj Husain, MDEnt Med, DMD $/$ / Fabiola Pessoa Pereira Leite, DDS $g$

aProfessor, Faculty Estacio de Sá, Faculty of Dentistry, Department of Restorative Dentistry, Juiz de Fora, Brazil

bStudent, Federal University of Juiz de Fora, Faculty of Dentistry, Department of Restorative Dentistry, Juiz de Fora, Brazil

¿Professor, University of Zurich, Dental Materials Unit, Center for Dental and Oral Medicine, Clinic for Fixed and Removable Prosthodontics and Dental Materials Science, Zurich, Switzerland aProfessor, Braz Cubas University, Faculty of Dentistry, Department of Dentistry, Mogi das Cruzes, Brazil eAssistant Professor, Federal University of Juiz de Fora, Faculty of Dentistry, Department of Dentistry, Governador Valadares, Brazil

fSpecialization Candidate, University of Bern, Department of Reconstructive Dentistry and Gerodontology, School of Dental Medicine, Bern, Switzerland gAssociate Professor, Federal University of Juiz de Fora, Faculty of Dentistry, Department of Restorative Dentistry, Juiz de Fora, Brazil

Short title: Air-abrasion protocols for yttrium stabilized zirconia

Correspondance to: Prof. Dr. med. dent. Mutlu Özcan, University of Zürich, Dental Materials Unit, Center for Dental and Oral Medicine Clinic for Fixed and Removable Prosthodontics and Dental Materials Science, Plattenstrasse 11, CH-8032, Zürich, Switzerland. Tel: +41-44-63 45600, e-mail: mutluozcan@hotmail.com 
Abstract: This study evaluated the effect of air-abrasion protocols on the topography, surface wettability and adhesion of resin cement to zirconia. Ceramic specimens $(\mathrm{N}=49 ; \mathrm{n}=7)(15 \mathrm{~mm} \times 2 \mathrm{~mm})$ were randomly allocated to 7 groups to be treated with: 1) Air-abrasion with $45 \mu \mathrm{m} \mathrm{Al} 2 \mathrm{O}_{3}(\mathrm{~A} 45)$, 2) $80 \mu \mathrm{m} \mathrm{Al} \mathrm{O}_{3}$ (A80), 3) 30 $\mu \mathrm{m} \mathrm{Al}_{2} \mathrm{O}_{3}$ coated with $\mathrm{SiO}_{2}$ (CoJet) (C30), 4) $30 \mu \mathrm{m} \mathrm{Al} 2 \mathrm{O}_{3}$ coated with $\mathrm{SiO}_{2}$ (Rocatec Soft) (R30), 5) $110 \mu \mathrm{m}$ $\mathrm{Al}_{2} \mathrm{O}_{3}$ coated with $\mathrm{SiO}_{2}$ (Rocatec Plus) (R110); 6) R110R30 (Rocatec) (R110R30) and 7) control, no conditioning (NC). Air-abrasion was performed using a chairside air-abrasion device (2.5 bar,10 mm, $90 \mathrm{~s}$ ). Contact angle measurements were performed using goniometry $(n=5)$. MDP-based dual resin cement (Panavia F2.0) was bonded on four locations after air-abrasion protocols ( $n=20$ per group). Half of the specimens were tested after $24 \mathrm{~h}$ and the other half after thermal cycling $\left(\times 3000,5-55^{\circ} \mathrm{C}\right)$. Data were analyzed using 1-, 2-way ANOVA and Tukey's test (alpha=0.05). Significantly lower contact angle values were observed for groups C30 (62.6 \pm 0.91$), R 30(61.91 \pm 1.05)$ and R110R30 (61.54 \pm 1.02$)$ compared to those of other groups $(65.5 \pm 0.9-$ $110.61 \pm 0.9)(p<0.05)$. In dry conditions, surface conditioning methods tested did not show significant effect on bond strength (MPa) $(10.57 \pm 1.42$ - 16.86 \pm 2.54$)(p=0.238)$. After thermocycling, bond strength results decreased significantly $(\mathrm{p}<0.05)(12.6-51.2 \%) . \mathrm{R} 110(7.18 \pm 1.34)$ and A80 $(4.92 \pm 1.53)$ showed significantly higher bond strength compared to other groups $(2.13 \pm 0.73-4.16 \pm 1.34)(p<0.05)$. The best wettability and adhesion results with MDP-based resin cement to zirconia was achieved with A80 and R110 air-abrasion. Keywords: Adhesion; Air-abrasion; Resin cements; Surface conditioning; Zirconium dioxide 


\section{Introduction}

Among ceramic materials, partially stabilized by yttria stabilized zirconia ceramic (Y-TZP; hereon: zirconia) undergo transformation change that is a property that allows for increased mechanical strength making the material suitable for the indications in load-bearing areas in reconstructive dentistry [1-4].

Since $f$ zirconia is composed of crystalline phase without silica, surface conditioning with $5-10 \%$ hydrofluoric acid is not effective for surface roughening [5]. For this reason, various surface conditioning methods have been proposed in order to improve the adhesion of resin cements to zirconia, among which are airborne particle abrasion with aluminium oxide $\left(\mathrm{Al}_{2} \mathrm{O}_{3}\right), \mathrm{Al}_{2} \mathrm{O}_{3}$ coated with silica $\left(\mathrm{Si}_{2} \mathrm{O}_{3}\right)$, application of specific primers or glazing the intaglio surface of zirconia reconstructions [5,6]. Current knowledge dictates that micromechanical retention through air-abrasion is still the most effective method for conditioning zirconia which could be accomplished either chairside or at the dental laboratory using particles at different sizes [7]. The effect of air-abrasion procedures on zirconia ceramic surface depends on the particle type, size, pressure and the distance of the nozzle to the surface $[8,9]$. $\mathrm{Al}_{2} \mathrm{O}_{3}$ particles of 50 to $250 \mu \mathrm{m}$ size are commonly used as they can be obtained at low costs globally. However, $\mathrm{Al}_{2} \mathrm{O}_{3}$ particles were reported to generate microcracks in ceramics [10]. The type and size of the particles used in conjunction with air-abrasion methods may affect the bond strength values where larger particles promote cracks in the material which may lead to failures at the adhesive interface $[11,12]$. On the contrary, smaller particles and those that are coated with silica may increase the adhesion of resin cements based on 10-Methacryloyloxydecyl dihydrogen phosphate monomer (MDP), with more hydrolytic stability [13]. Due to the impact during air-abrasion, silica layer on the alumina particles remain attached on the surface [12], which then reacts with the adhesive promoter or resin cement, a process called silicatization [13]. While laboratory air-abrasion system is based on utilizing $110 \mu \mathrm{m}$ alumina particles to clean and roughen the surface followed by the application of $30 \mu \mathrm{m}$ silica particles (Rocatec, 3M ESPE), the chairside application of the same method is based on deposition of $30 \mu \mathrm{m}$ silica particles only (CoJet, 3M ESPE). The particle size and morphology may impair mechanical stability of zirconia where larger particles were reported to cause more monoclinical phase transformation $[11,12]$. Recently, 
similar air-abrasion methods are employed for roughening zirconia implant surfaces and there is limited information available on the best deposition method and particle size to achieve increased wettability which is crucial for the osseointegration.

The objectives of this study therefore were to study the effect of air-abrasion protocols on the topography, surface wettability, adhesion of MDP-based resin cement to zirconia and evaluate failure types after debonding. The null hypothesis tested was that particle size would not significantly affect the surface wettability and adhesion of resin cement tested to zirconia.

\section{Materials and Methods}

\section{Specimen preparation}

Zirconia specimens ( $\mathrm{N}=49)$ were fabricated according to the manufacturer's recommendations (LAVA AllCeramic System, 3M ESPE, St. Paul, USA) (diameter: $15 \mathrm{~mm}$; thickness: $2 \mathrm{~mm}$ ). The specimen surfaces were finished using silicon carbide papers under water-cooling in the order of $800,1200,1500,2000$-grit prior to sintering. The specimens were randomly divided into 7 groups depending on the surface conditioning methods:

\section{Surface conditioning methods}

Air-abrasion was carried out using a chairside device (Microjato Standard, Bioart, Sao Paolo, Brasil) [14] operating at 2.5 bar from a distance of $10 \mathrm{~mm}$ in circular motions for $90 \mathrm{~s}$ with the following particles: 1) $45 \mu \mathrm{m}$ $\mathrm{Al}_{2} \mathrm{O}_{3}$ (A45) (Polidental, São Paulo, Brasil), 2) $80 \mu \mathrm{m} \mathrm{Al} 2 \mathrm{O}_{3}$ (A80) (Polidental), 3) $30 \mu \mathrm{m} \mathrm{Al} 2 \mathrm{O}_{3}$ coated with $\mathrm{SiO}_{2}$ (CoJet, 3M ESPE) (C30), 4) $30 \mu \mathrm{m} \mathrm{Al} 2 \mathrm{O}_{3}$ coated with $\mathrm{SiO}_{2}$ (Rocatec Soft) (R30) (3M ESPE), 5) $110 \mu \mathrm{m} \mathrm{Al} \mathrm{O}_{3}$ coated with $\mathrm{SiO}_{2}$ (Rocatec Plus, 3M ESPE) $(\mathrm{R} 110,6) \mathrm{R} 110+\mathrm{R} 30$ (Rocatec System, 3M ESPE) (R110R30), and 7) control, no conditioning (NC).

\section{Surface wettability measurements}

Two specimens from each group were selected and contact angle measurements were performed using a goniometer (Contact Angle Goniometer, Rame-Hart Inc., Montain Lakes, USA) at controlled temperature and humidity. Measurements were made using the corresponding software (RHI 2001 Software Imaging, Montain 
Lakes, USA). A drop of deionized water was applied on the ceramic surface using a syringe and the contact angle was measured for $20 \mathrm{~s}$ (30 frames per second) after the initial break of $10 \mathrm{~s}$.

\section{Bonding procedures}

After surface conditioning, a tape with three holes were placed (diameter: $3 \mathrm{~mm}$ ) (Scotch Tape, 3M ESPE, Sumare, SP, Brazil) on the zirconia specimens. Then, silane coupling agent was applied one coat (Monobond

S, Ivoclar Vivadent, Schaan, Liechtenstein) with a microbrush (Vigodent, Rio de Janeiro, RJ, Brazil), waited for its reaction for $60 \mathrm{~s}$ and then air-dried for $20 \mathrm{~s}$. On each hole a cylindrical transparent plastic mould (SaintGobain Performance Plastic, Maime Lakes, FL, USA) was fixed (inner diameter: $3 \mathrm{~mm}$; height: $3 \mathrm{~mm}$ ) with cyanoacrylate gel (Super Glue, Loctite, Diadema, SP, Brazil). MDP containing resin cement (Panavia F2.0, Kuraray, Okayama, Japan) was applied into the mould with the aid of a centrix syringe (AccuDose needle, Polidental Ind. E Com. Ltd., São Paulo, Brazil). Resin cement was photo-polymerized using an LED polymerization device (Tygon Radii-Cal LED, SDI Pines, SP, Brazil) at an intensity of $1200 \mathrm{~mW} / \mathrm{cm} 2$ for $40 \mathrm{~s}$ from each side. After removal of moulds, half of the specimens were tested after $24 \mathrm{~h}$ and the other half after thermal cycling $\left(\times 3000,5-55^{\circ} \mathrm{C}\right.$; dwelling time in each bath: 30 s) (Ética Equipamento Científicos S/A, São Paulo, Brasil).

\section{Macroshear tests}

The specimens were loaded under shear at the ceramic-resin interface in a Universal Testing Machine (EMIC DL-2000, Company, Sao Paolo, Brasil) using a wire (diameter: $0.4 \mathrm{~mm}$ ) around the cement, making contact with the substrate. The shear force $(20 \mathrm{Kgf})$ was applied at a cross-head speed of $0.5 \mathrm{~mm} / \mathrm{min}$ until failure.

\section{Microscopic examination and failure analysis}

After each air-abrasion protocol, images were made ( $n=2$ per group) from 2 randomly selected specimens using Scanning Electron Microscope (SEM) (JSM-5600 LV, Jeol, Tokyo, Japan) in order to observe topographical changes [15].

After adhesion tests, the debonded specimen surfaces were examined in order to analyze the failure types using an optical microscope (Zeiss MC 80 DX, Jena, Germany) at x50 magnification. Failure types were 
planned to be classified as follows: Score 1: Adhesive failure at the ceramic-cement interface with no cement remnants left on the substrate, Score 2: Cohesive failure within the cement, Score 3: Cohesive failure within the substrate, Score $4:<1 / 3$ cement left adhered on the substrate.

\section{Statistical analysis}

Statistical analysis was performed using Statistica 8.0 software for Windows (StatSoft, Inc., Tulsa, OK, USA). Kolmogorov-Smirnov and Shapiro-Wilk tests were used to test normal distribution of the data. As the data were normally distributed, 2-way ANOVA and Tukey`s tests were used where the bond strength was the dependent variable and conditioning methods (7 levels: A45, A80, C30, R30, R110, R110R30, NC), and aging types (2 levels: dry versus thermocycle) as independent variables. In addition, 1-way ANOVA and Tukey`s tests were used for the statistical analysis of the wettability data. $P$ values less than 0.05 were considered to be statistically significant in all tests.

\section{Results}

Air-abrasion type influenced the contact angle values and bond strength results significantly $(p<0.05)$. Interaction terms were also significant $(p<0.05)$.

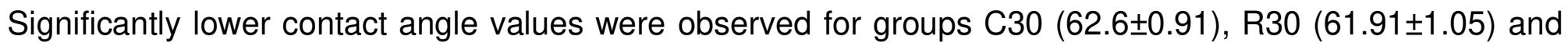
R110R30 (61.54 \pm 1.02$)$ compared to those of other groups $(65.5 \pm 0.9-110.61 \pm 0.9)(p<0.05)$ (Table 1). Mean contact angle value was significantly higher in the control group $(110.61 \pm 0.9)(p<0.05)$.

In dry conditions, surface conditioning methods tested did not show significant effect on bond strength $(10.57 \pm 1.42-16.86 \pm 2.54 \mathrm{MPa})(\mathrm{p}=0.238)$ (Table 2). After thermocyling, bond strength results decreased significantly in all groups $(p<0.05)$ ranging between 12.6 to $51.2 \%$ (Fig. 1 ).

Among all air-abraded groups, R110 (7.18 \pm 1.34$)$ and A80 (4.92 \pm 1.53$)$ showed significantly higher bond strength values compared to other groups $(2.13 \pm 0.73-4.16 \pm 1.34 \mathrm{MPa})(\mathrm{p}<0.05)$.

Failure types were exclusively adhesive in all groups. 
SEM images (x2000) showed evident traces of silicon carbide paper in the control group and in A45, A80, C30, R30 specimens while the increase in particle size ( R110 and R110R30) created more number of grooves and irregularities (Figs. 2a-g). No cracklines were observed in any of the specimens.

\section{Discussion}

This study evaluated the effect of air-abrasion protocols on the topography, surface wettability, adhesion of MDP-based resin cement to zirconia. Based on the results of this study, since air-abrasion method significantly affected the surface wettability and adhesion of resin cement tested, the null hypothesis could be rejected.

Reliable adhesion between the resin cement and zirconia is a prerequisite especially for the clinical longevity of minimal invasive reconstructions $[15,16]$. Studies have focused on the selection of cement types in order to obtain adequate adhesion to intaglio surfaces of zirconia frameworks $[15,17,18]$ but the most appropriate cementation protocol is not yet consolidated [19]. Due to its composition, microstructure and physical properties, durable adhesionwith conventional cements could not be obtained and therefore zirconia surfaces need to be conditioned prior to cementation [7,20-22]. Among the proposed surface conditioning methods, especially air-abrasion protocols have been reported to increase the surface area and surface energy and promote mechanical microretentions that allow for cement interlocking $[9,22-24]$. Morphological changes through air-abrasion also alter wettability of the substrate surface [25]. These findings are confirmed in this study where higher wettability and adhesion was obtained after air-abrasion protocols when compared to the non-conditioned control group.

In the literature, while some studies reported favourable results with the use of aluminum oxide particles $[8,23,26,27]$, others suggested that such particles may damage zirconia creating microcracks and thereby reducing the mechanical resistance of restorations by 20 to $30 \%[10,11,28,29]$. These aspects are directly related to the size and type of particles employed during air-abrasion. According to Kosmac et al., aluminum oxide could remove a layer of $60 \mu \mathrm{m}$ from the ceramic surface [30]. This superficial damage, although microscopic, negatively influences the mechanical stability of zirconia $[31,32]$. Moreover, excessively high 
pressure practiced during air-abrasion may initiate phase transformation, and accelerate crack formation [10]. Likewise, particle size and deposition duration may also affect the stability of zirconia [10,33-35]. Given this fact, in this study particle deposition was achieved under the same pressure, nozzle distance and duration while particle size varied.

In fact, high-strength ceramics such as zirconia are hard materials and therefore they cannot be effectively air-abraded $[36,37]$. For this reason, abrasion with larger particles produce more roughness, and hence better micromechanical retention. According to results obtained after thermocycling, A80 and R110 groups delivered statistically similar bond strength values, being higher than those of other groups. Similarly, Özcan et al. found no statistical differences between $\mathrm{Al}_{2} \mathrm{O}_{3}$ and $\mathrm{Al}_{2} \mathrm{O}_{3}$ coated with $\mathrm{SiO}_{2}$ in dry conditions but after thermocycling the latter showed less hydrolytic degradation [19]. In this study, A80 containing less aggressive particles compared to $110 \mu \mathrm{m}$ helped for better wettability and therefore less decrease in bond strength.

The increase in surface energy of zirconia after mechanical and chemical conditioning may improve the union between the resin-based cements and zirconia [38]. The topographic features observed in A80 and R110 groups with larger particles produce greater irregularities, and hence higher surface roughness [14],. It should be noted that local changes in the surface energy of solid substrates may affect contact angle values. In this context, wettability properties change as a function of contact angle hysteresis. Hence, rough surfaces tend to show high hysteresis of contact angle by air entrapment in the deeper parts of the valleys created by the particles. This fact may explain the differences in values observed for A45 groups, R30 and C30 where more homogeneous surfaces were observed.

R110R30 particle type on the other hand, combines the advantages of larger and smaller particles. However, contact angle, bond strength values and topographical changes observed with this particle type were similar to groups with smaller particles namely, $\mathrm{R} 30$ and $\mathrm{C} 30$. While air-abrasion with $\mathrm{Al}_{2} \mathrm{O}_{3}$ coated $\mathrm{SiO}_{2}$ provides ultrafine mechanical retention and welding of silica particles [17], these particles may detach from the surface over time $[13,22,27,39]$. One other factor is the hydrolytic degradation of zirconia-resin cement interface $[27,40,41]$. This could explain the reasons for the loss of bond strength in this study after aging which supports previous findings 
$[13,42,43]$. In this study, thermocycling was limited to 3000 cycles based on pilot studies but prolonged number of cycles may further decrease the achieved results.

As for the analysis of failures, all groups presented adhesive failures. The absence of cohesive or mixed failures $[16,44-46]$ demonstrates that the shear stress applied to the zirconia-resin interface could detach the cement from the zirconia surface completely which is an indication of insufficient adhesion to zirconia.

Based on the results of this study, it is worth noting that the different particle size and morphology directly affected the wettability and bond strength results. Although particle deposition with smaller particles resulted in more homogeneous surface topography and increased wettability, bond strength results after aging were higher for the groups conditioned with larger particles. To the authors' best knowledge, this is the first study that investigated all types of sand particles ranging from small to large size available for laboratory and chairside applications in one study. Especially the use of $80 \mu \mathrm{m} \mathrm{Al} \mathrm{O}_{3}$ (A80) has not been studied in earlier studies. Since silica coated alumina particles are not available universally, based on non-significant results, the use of A80 could substitute CoJet or Rocatec systems. Clinical studies should verify whether the achieved bond strength results are sufficient for longevity of minimal invasive zirconia reconstructions and the wettability results for biological interactions with zirconia implants.

\section{Conclusions}

From this study, the following could be concluded:

1- The non-conditioned control group resulted in the least wettability and delivered the lowest bond strength values of the tested MDP-based resin cement to zirconia.

2- In non-aged conditions, all types of air-abrasion particles tested showed similar bond strength results.

3- Aging decreased the bond strength results after all air-abraded groups with the A80 and R110 showing the highest results. 


\section{Clinical Relevance}

Air-abrasion of zirconia surfaces increased the wettability and adhesion of 10-MDP based resin cement. Aging

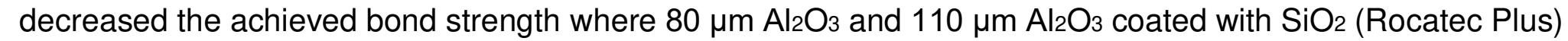
showed the highest bond strength. Yet, failure types were adhesive in all groups, indicating weak adhesion to zirconia.

\section{Acknowledgement}

This study is part of a thesis presented by Vivian Espirito Santo Massi by Paschoalino (2014) (First Advisor: F.P.P. Leite and the Co-Advisor: R.F. de Carvalho) at the Federal University of Juiz de Fora, Brazil.

\section{Conflict of interest}

The authors did not have any commercial interest in any of the materials used in this study. 


\section{References}

[1] Guzzato M, Quach L, Albakry M, et al. Influence of surface and heat treatments on the flexural strength of Y-TZP dental ceramic. J. Dent. 2005;33:9-18.

[2] Beuer F, Edelhoff D, Gernet W, et al. Three-year clinical prospective evaluation of zirconia-based posterior fixed dental prostheses (FDPs). Clin. Oral. Invest. 2009;13:445-445.

[3] Bonfante EA, Sailer I, Silva NRSA, et al. Failure modes of Y-TZP crowns at different cusp inclines. J. Dent. 2010;38:707-712.

[4] Keuper M, Berthold C, Nickel KG. Long-time aging in 3 mol.\% yttria-stabilizedtetragonal zirconia polycrystals at human body temperature. Acta. Biomater. 2014;10:951-959.

[5] May LG, Passos SP, Capelli DB, et al. Effect of silica coating combined to a MDP-based primer on the resin bond to Y-TZP ceramic. J. Biomed. Mater. Res. B. Appl. Biomater. 2010;95:69-74.

[6] Vanderlei A, Bottino M, Valandro L. Evaluation of Resin Bond Strength to yttria-stabilized tetragonal zirconia and framework marginal fit: comparison of different surface conditionings. Oper. Dent. 2014;39:50-63.

[7] Thompson JY, Stoner BR, Piascik JR, et al. Adhesion/cementation to zirconia and other non-silicate ceramics:where are we now? Dent. Mater. 2011;27:71-82.

[8] Monaco C, Cardelli P, Scotti R et al. Pilot evaluation of four experimental conditioning treatments to improve the bond strength between resin cement and Y-TZP ceramic. J. Prosthodont. 2011;20:97-100.

[9] Casucci A, Mazzitelli C, Monticelli F et al. Morphological analysis of three zirconium oxide ceramics: Effect of surface treatments. Dent. Mater. 2010;26:751-760.

[10] Sato H, Yamada K, Pezzotti G et al. Mechanical properties of dental zirconia ceramics changed with sandblasting and heat treatment. Dent. Mater. 2008;27:408-414. 
[11] Souza ROA, Valandro LF, Melo RM, et al. Air-particle abrasion on zirconia ceramic using different protocols: effects on biaxial flexural strength after cyclic loading, phase transformation and surface topography. J. Mech. Behav. Biomed. Mater. 2013;26:155-163.

[12] Campos F, Souza RO, Bottino MA, et al. Fracture strength, failure types, and weibull characteristics of three-unit zirconia fixed dental prostheses after cyclic loading: effects of veneering and air-abrasion protocols. Int. J. Periodontics. Restorative. Dent. 2016;36:901-908.

[13] De Castro HL, Corazza PH, Paes-Junior TdeA, et al. Influence of Y-TZP ceramic treatment and different resin cements on bond strength to dentin. Dent. Mater. 2012;28:1191-1197.

[14] Amaral R, Özcan M, Bottino MA et al. Microtensile bond strength of a resin cement to glass infiltrated zirconia-reinforced ceramic:the effect of surface conditioning. Dent. Mater. 2006;22:283-290.

[15] Paschoalino VESM, De Carvalho RF, Leite FPP. Efeito de diferentes protocolos de jateamento sobre a durabilidade de união de uma cerâmica ao cimento resinoso. 2014 PhD thesis, Federal University of Juiz de Fora, Brazil.

[16] Burke FJ, Flemming GI, Nathanson D, et al. Are adhesive technologies needed to support ceramics? An assessment of the current evidence. J. Adhes. Dent. 2002;4:7-22.

[17] Blatz MB, Sadan A, Kern M. Resin-ceramic bonding: a review of the literature. J. Prosthet. Dent. 2003;89:268-274.

[18] De Oyagüe RC, Monticelli F, Toledano M, et al. Influence of surface treatments and resin cement selection on bonding to densely-sintered zirconium-oxide ceramic. Dent. Mater. 2009;25:172-179.

[19] De Souza GMD, Silva NRFA, Paulillo LAMS, et al. Bond strength to high-crystalline contentzircôniaafter different surface treatments. J. Biomed. Mater. Res. B. Appl. Biomater. 2010;93:318-323. 
[20] Kern M, Wegner SM.Bonding to zirconia ceramic:adhesion methods and their durability. Dent Mater. 1998;14:64-71.

[21] Özcan M, Nijhuis H, Valandro LF. Effect of various surface conditioning methods on the adhesion of dualcure resin cement with MDP functional monomer to zirconia after thermal aging. Dent. Mater. J. 2008;27:99104.

[22] Sabatini C, Patel M, D'Silva E. In vitro shear bond strength of three self-adhesive resin cements and a resin-modified glass ionomer cement to various prosthodontic substrates. Oper. Dent. 2013;38:186-196.

[23] Re D, Augusti D, Sailer I, et al. The effect of surface treatment on the adhesion of resin cements to Y-TZP. Eur. J. Esthet. Dent. 2008;3:186-196.

[24] Blatz MB, Phark JH, Ozer F, et al. In vitro comparative bond strength of contemporary self-adhesive resin cements to zirconium oxide ceramic with and without air-particle abrasion. Clin. Oral. Investig. 2010;14:187192.

[25] Gomes AL, Castillo-Oyagüe R, Lynch CD, et al. Influence of sandblasting granulometry and resin cement composition on microtensile bond strength to zirconia ceramic for dental prosthetic frameworks. J. Dent. 2013;41:31-41.

[26] Arsu SS, Kilicarslan MA, Kucukesmen HC, et al. Effect of zirconium-oxide ceramic surface treatments on the bond strength to adhesive resin. J. Prosthet. Dent. 2006;95:430-436.

[27] Cavalcanti AN, Foxton RM, Watson TF, et al. Bond strength of resin cements to a zirconia ceramic with different surface treatments. Oper. Dent. 2009;34: 280-287.

[28] Guazzato M, Albakry M, Ringer SP, et al. Strength, fracture toughness and microstructure of a selection of all-ceramic materials. Part I.Pressable and alumina glass-infiltrated ceramics. Dent. Mater. 2004;20;441448. 
[29] Kulunk S, Kulunk T, Ural C, et al. Effect of air abrasion particles on the bond strength of adhesive resin cement to zirconia core. Acta. Odontol. Scand. 2011;69:88-94.

[30] Zhang W, Masumi SI, Song XM. Bonding property of two resin-reinforced glass-ionomer cements to zirconia ceramic. Quintessence. Int. 2010;41:132-140.

[31] Kosmac T, Oblak C, Jevnikar P, et al. Strength and reliability of surface treated Y-TZP dental ceramics. J. Biomed. Mater. Res. 2000;53:304-313.

[32] Scarano A, Piatelli M, Caputi S, et al. Bacterial adhesion on commercially pure titanium and zirconium oxide disks: an in vivo human study. J. Periodontol. 2004;75:292-296.

[33] Heikkinen TT, Lassila LV, Matinlinna JP, et al. Effect of operating air pressure on tribochemical silicacoating. Acta. Odontol. Scand. 2007;65:241-248.

[34] Studart AR, Filser F, Kocher P, et al. Cyclic fatigue in water of veneer-framework composites forall-ceramic dental bridges. Dent. Mater. 2007;23:177-185.

[35] Sousa RS, Campos F, Sarmento HR, et al. Surface roughness and bond strength between Y-TZP and self-adhesiv resin cement after air particle abrasion protocols. Gen. Dent. 2016;64:50-55.

[36] Michida SM, Valandro LF, Yoshiga S, et al. Effect of surface treatment of a glass-infiltrated alumina ceramic on the microtensile bond strength. J. Appl. Oral. Sci. 2003;11:361-366.

[37] Guess PC, Zahng Y, Kim JW, et al. Damage and reliability of Y-TZP after cementation surface treatment. J. Dent. Res. 2010;592-596.

[38] Matinlinna JP, Lassila LV. Enhanced resin-composite bonding to zirconia framework after pretreatment with selected silane monomers. Dent. Mater. 2011;27:273-280. 
[39] Della Bona A, Donassollo TA, Demarco FF. Characterization and surface treatment effects on topography of a glass-infiltrated alumina/zirconia-reinforced ceramic. Dent. Mater. 2007;23:769.

[40] Manicone PF, Rossi lommetti P, et al. An overview of zirconia ceramics: basic properties and clinical applications. J. Dent. 2007;35:819-826.

[41] Chen L, Suh BI, Kim J, et al. Evaluation of silica-coating techniques for zirconia bonding. Am. J. Dent. $2011 ; 24: 79-84$.

[42] De Castro HL, Corazza PH, Paes-Junio TA, et al. Influence of Y-TZP ceramic treatment and different resin cements on bond strength to dentin. Dent. Mater. 2012;28:1191-1197.

[43] Passos SP, May LG, Barca DC, et al. Adhesive quality of self-adhesive and conventional adhesive resin cement to Y-TZP ceramic before and after aging conditions. Oper. Dent. 2010;35:689-696.

[44] Della Bona A, Borba M, Benetti $P$, et al. Effect of surface treatments on the bond strength of a zirconiareinforced ceramic to composite resin. Braz. Oral. Res, 2007;21:10-15.

[45] Qeblawi DM, Munoz CA, Brewer JD, et al. The effect of zirconia surface treatment on flexural strength and shear bond strength to a resin cement. J. Prosthet. Dent. 2010;103:210-220.

[46] Kim MJ, Kim YK, Kim KH, et al. Shear bond strengths of various luting cements to zirconia ceramic: surface chemical aspects. J. Dent. 2011;39:795-803. 


\section{Captions to figures and tables:}

\section{Tables:}

Table 1. Mean \pm standard deviations of the contact angle $\left({ }^{\circ}\right)$ measurements. Different superscript letters in one

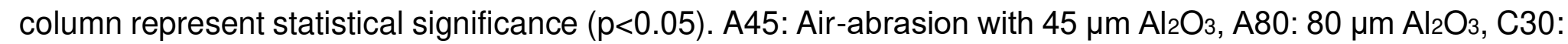
$30 \mu \mathrm{m} \mathrm{Al} 2 \mathrm{O}_{3}$ coated with $\mathrm{SiO}_{2}$ (CoJet), $\mathrm{R} 30: 30 \mu \mathrm{m} \mathrm{Al} 2 \mathrm{O}_{3}$ coated with $\mathrm{SiO}_{2}$ (Rocatec Soft), R110: $110 \mu \mathrm{m} \mathrm{Al} \mathrm{O}_{3}$ coated with $\mathrm{SiO}_{2}$ (Rocatec Plus), R110R30: R110+R30 (Rocatec System), NC: Control no conditioning.

Table 2. Mean macroshear bond strength values (MPatstandard deviations) without and with thermocycling. *Uppercase letters in one column represent statistical significant differences and lower case letters in one row $(p<0.05)$. See Table 1 for group abbreviations.

\section{Figures:}

Fig. 1 Bond strength change in percentage between non-aged and aged groups.

Figs. 2a-g SEM images (x2000) of a) NC, b) A45, c) A80, d) C30, e) R30, f) R110, g) R110R30. Note the evident traces of silicon carbide paper in the control group and in A45, A80, C30, R30 specimens while the increase in particle size with R110 and R110R30 created more roughness and surface irregularities. See Table 1 for group abbreviations. 


\section{Tables:}

Experimental Groups

Contact Angle ( $\left.{ }^{\circ}\right)$

\begin{tabular}{|r|c|}
\hline & Mean \pm Standard Deviation \\
\hline NC & $110.61 \pm 0.9 \mathrm{a}$ \\
\hline A80 & $65.50 \pm 0.94 \mathrm{~d}$ \\
\hline C30 & $78.37 \pm 0.62 \mathrm{c}$ \\
\hline R30 & $62.66 \pm 0.91$ de \\
\hline R110 & $61.91 \pm 1.05 \mathrm{e}$ \\
\hline R110R30 & $80.68 \pm 0.84 \mathrm{~b}$ \\
\hline
\end{tabular}

Table 1. Mean \pm standard deviations of the contact angle $\left({ }^{\circ}\right)$ measurements. Different superscript letters in one column represent statistical significance $(\mathrm{p}<0.05)$. A45: Air-abrasion with $45 \mu \mathrm{m} \mathrm{Al} \mathrm{O}_{3}, \mathrm{~A} 80: 80 \mu \mathrm{m} \mathrm{Al} 2 \mathrm{O}_{3}, \mathrm{C}_{30}: 30 \mu \mathrm{m} \mathrm{Al} 2 \mathrm{O}_{3}$ coated with $\mathrm{SiO}_{2}$ (CoJet), R30: $30 \mu \mathrm{m} \mathrm{Al} 2 \mathrm{O}_{3}$ coated with $\mathrm{SiO}_{2}$ (Rocatec Soft), R110: $110 \mu \mathrm{m} \mathrm{Al} \mathrm{O}_{3}$ coated with $\mathrm{SiO}_{2}$ (Rocatec Plus), R110R30: R110+R30 (Rocatec System), NC: Control no conditioning.

\begin{tabular}{ccc}
\hline Experimental Groups & Dry & Thermocycling \\
\hline NC & Mean \pm Standard Deviation & Mean \pm Standard Deviation \\
A45 & $10.5 \pm 1.42 \mathrm{Aa}$ & $1.86 \pm 0.30 \mathrm{cb}$ \\
A80 & $14.38 \pm 2.96 \mathrm{Aa}$ & $3.75 \pm 1.94 \mathrm{Bb}$ \\
C30 & $12.41 \pm 2.08 \mathrm{Aa}$ & $4.92 \pm 1.53 \mathrm{Ab}$ \\
R30 & $16.86 \pm 2.54 \mathrm{Aa}$ & $2.13 \pm 0.73 \mathrm{cb}$ \\
R110 & $13.98 \pm 3.55 \mathrm{Aa}$ & $4.16 \pm 1.34 \mathrm{Bb}$ \\
R110R30 & $14.01 \pm 2.03 \mathrm{Aa}$ & $7.17 \pm 1.34 \mathrm{Ab}$ \\
\end{tabular}

Table 2. Mean macroshear bond strength values (MPa \pm standard deviations) without and with thermocycling. *Uppercase letters in one column represent statistical significant differences and lower case letters in one row $(p<0.05)$. See Table 1 for group abbreviations. 
Figures:

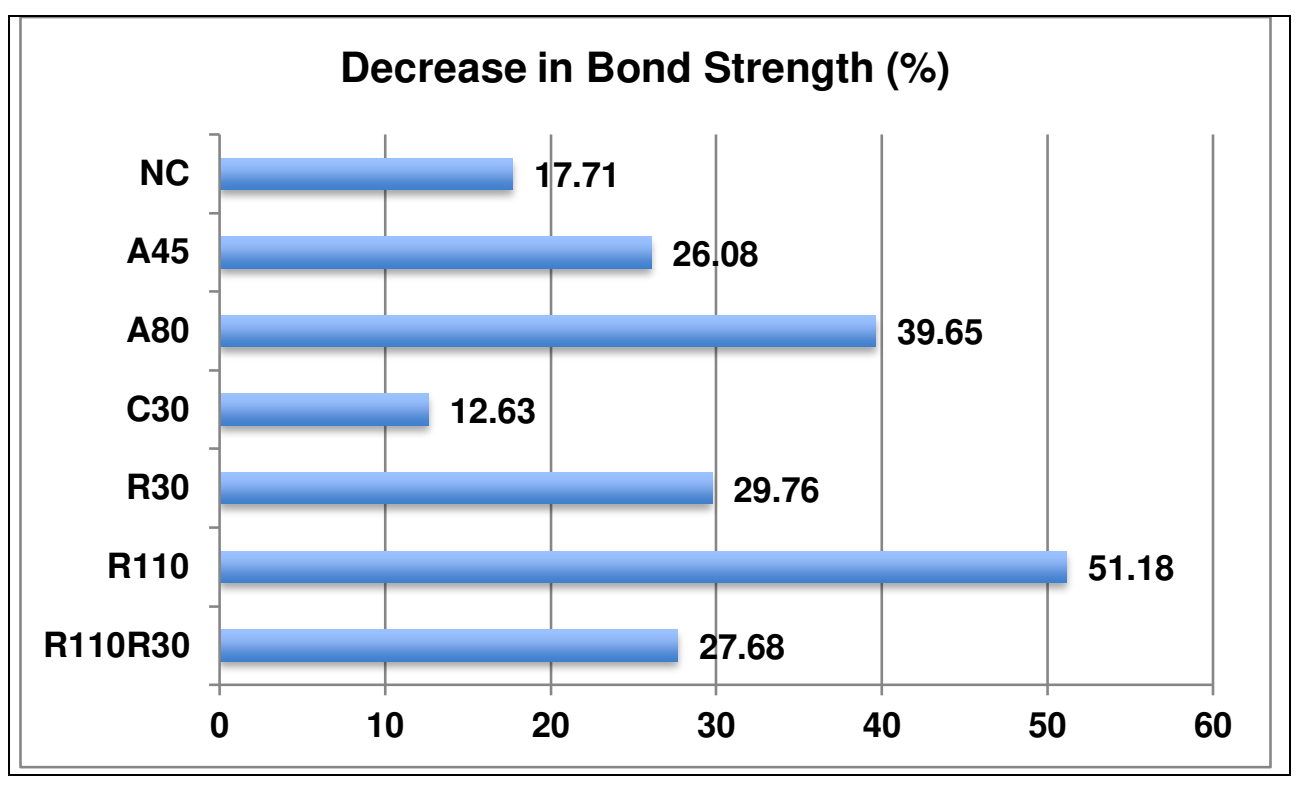

Fig. 1 Bond strength change in percentage between non-aged and aged groups.

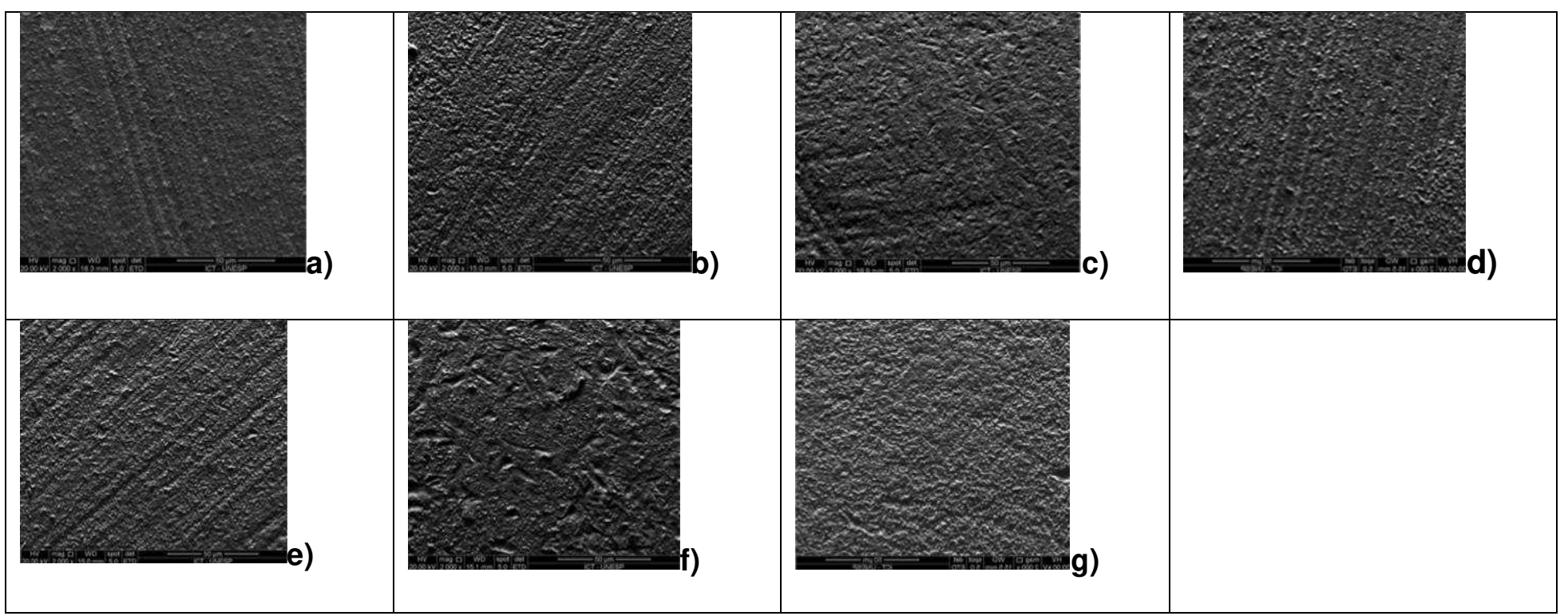

Figs. 2a-g SEM images (x2000) of a) NC, b) A45, c) A80, d) C30, e) R30, f) R110, g) R110R30. Note the evident traces of silicon carbide paper in the control group and in A45, A80, C30, R30 specimens while the increase in particle size with R110 and R110R30 created more roughness and surface irregularities. See Table 1 for group abbreviations. 